ISBN 978-93-84422-76-9

6th International Conference on Developments in Engineering and Technology

(ICDET-2017)

Bangkok (Thailand) Feb.6-7, 2017

\title{
A Study on the Estimating Dam Suitable Site based on Geographic Information using AHP
}

\author{
Tai Ho Choo ${ }^{1}$, SI Hyung Ahn ${ }^{1}$, Da Un Yang ${ }^{1}$ and Gwan Seon Yun ${ }^{1}$ \\ ${ }^{1}$ Department of Civil and Environmental Engineering, Pusan National University
}

\begin{abstract}
South Korea is disadvantageous to manage water resource seasonally, topographically and geographically, also frequency of climate change and abnormal climate due to global warming is a growing trend. Therefore, limited water resource is utilized economically to correspond climate change, a study for solution reducing water disaster, such as drought and flood, is needed. Thus, in the present study, we carried out a dam that could secure water resources. Based on geographic information map such as river map, land cover map, geologic map, digital elevation map and slope map, the functional formula is developed to determine suitable dam site using weighting method and overlapping for each parameter.
\end{abstract}

Keywords: AHP technique, overlapping method, suitable dam site, securing water resources

\section{Introduction}

According to the precipitation characteristics of South Korea, climate change trend shows that annual precipitation has increased by more than $16 \%$ from $1,230 \mathrm{~mm}$ in the $1970 \mathrm{~s}$ to $1,432 \mathrm{~mm}$ in recent years, and drought has occurred frequently at intervals of five to seven-year since 1970 (Choo et al., 2015). Annual precipitation occurs more than $60 \%$ in the summer season, and the frequency of local rainfall which is concentrated in a specific area in a short period of time is increasing. Also, rainfall characteristics is irregular, so it is difficult to forecast and manage water resources including water use and flood prevention. The dam mainly consists of reservoirs built over the path of water flow to store water, and it provides a great benefit to mankind (Raheem et al, 2002; Iftikhar, 2016). In the case of multi-purpose dams, the flood control of the downstream area is reduced by securing the flood control capacity before large rainfall events occur by using a large basin. Water resources is secured through the operation of the dam by effectively distributing, and a dam has a net function to supply the water in case of drought season. Therefore, the present study proposed a function formula of estimating suitable dam site using existing geographic information map such as soil map, land cover map, digital elevation map, river map, geologic map and so on. It is expected that could save time, cost and manpower.

\section{Research background}

We investigated studies on estimating suitable site or facilities on using GIS. Park and Choi (1997) conducted land conformity analysis on the development level for Yeoncheon-gun, And analysis of development grade and use district. Lee et al. (2001) analysed the suitability of land use by classifying the natural environment according to the use area of Gumi-si and setting evaluation criteria. In addition, Lili et al. (2009) used GIS and weight overlap to evaluate the vulnerability of local landslides, Lee et al. (2015) conducted research on a method of selecting suitable area groundwater artificial recharge by utilizing geographical space data such as watershed fragmentation images, slope map, emotional images and DEM. Saaty (2008) proposed an AHP analysis system with a hierarchical structure, pair wise comparison matrix, a calculation of comparative 
importance, a verification of logical consistency, and a four-stage structure of priority and weighting. AHP technique represents the process of constructing a structure based on the values of the problem, constructing pair wise comparison matrix, calculating the relative weighting method of the characteristic calculation method, and compiling the priority of the evaluation metrics through consistency verification. As above, GIS were developed and propagated, and then spatial information maps were built up in various fields and actively used. Studies on estimating suitable site of particular facilities using fuzzy logic, assessment level, weighting method using AHP technique, overlapping and so on were being investigated.

\section{Research Contents}

\subsection{Method of study}

A suitable site analysis is to select an area that meets a given condition. The general process of site analysis consists of setting analysis goals and indicators, collecting and constructing analysis data, identifying opportunities and constraints, grading analysis factors, weighting, overlaying plans, reviewing and reflecting results, finally selection of suitable site can be distinguished in order. AHP is a methodology for objectifying subjective thoughts by capturing the knowledge, experience and intuition of various evaluators through judgment by pairwise comparison between the elements constituting hierarchical structure of decision making. Through these procedure, we suggested a functional formula to select a dam site. In order to determine the index for selecting the dam site, the domestic dam and its location were surveyed and the dam watershed using GIS was analysed firstly. Then, the selected index was selected through the existing literature survey and the weight of the evaluation index was given through the questionnaire survey and AHP analysis. The functional formula is applied to study area and calibrated and verified.

\subsection{Analysis of dam watersheds using GIS}

We carried out slope analysis about 66 Dam watersheds of standard watershed unit of constructed in Korea using GIS. The Geological map shows the kind of rocks and rocks distribution in some area, geological structure, inclination, location of mines et and is a map showing the type and age distribution of rocks in some areas, geological structure, inclinations and slopes, location of mines and so on. The land cover map shows the areas with homogeneous characteristics by examining and classifying the physical form of the surface according to certain criteria. The river map represents the area where the rainfall flows when the rainfall flows out to the surface. Low value of stream order tend to upstream of watershed and main stream has high value. First-order stream meets other one, the stream order turn into second-order stream. The slope map that the slope of surface and river bed are presented quantitative numerical value is one of the important factors influencing the rainfall runoff and river flow

\subsection{Selection of assessment indexes}

In order to derive appropriate results with considering the topographic parameters, we determined the evaluation index through hydrogeological map, land cover map, slope, river map, stream order map and literature investigation of the standard watershed unit of Dam watershed. The evaluation index consisted of land cover (LC), hydrological geology (GE), slope (SL), river (RI), and topography (GE). The topographical information map for evaluating evaluation index is land cover, hydrological geology, slope, river and stream number, and topographic map.

\subsection{Composition of assessment indexes with weighting 3.5. Stratification of assessment indexes}

In order to assign weights to each of the above-mentioned evaluation indexes, we constructed a total of three indicators (Fig. 1). Level 3 consists of two grades to seven grades to give a score on the level 2 indicator as mentioned above. Level 2 is a step of assigning weights by evaluating the importance of each other by using land cover (LC), hydrological geology (GE), slope (SL), river (RI) and terrain (TP). Finally, the most important first stage is evaluate suitability for the dam by integrating elements of decision making based the objective. 


\section{Level $1 \quad$ Level 2}

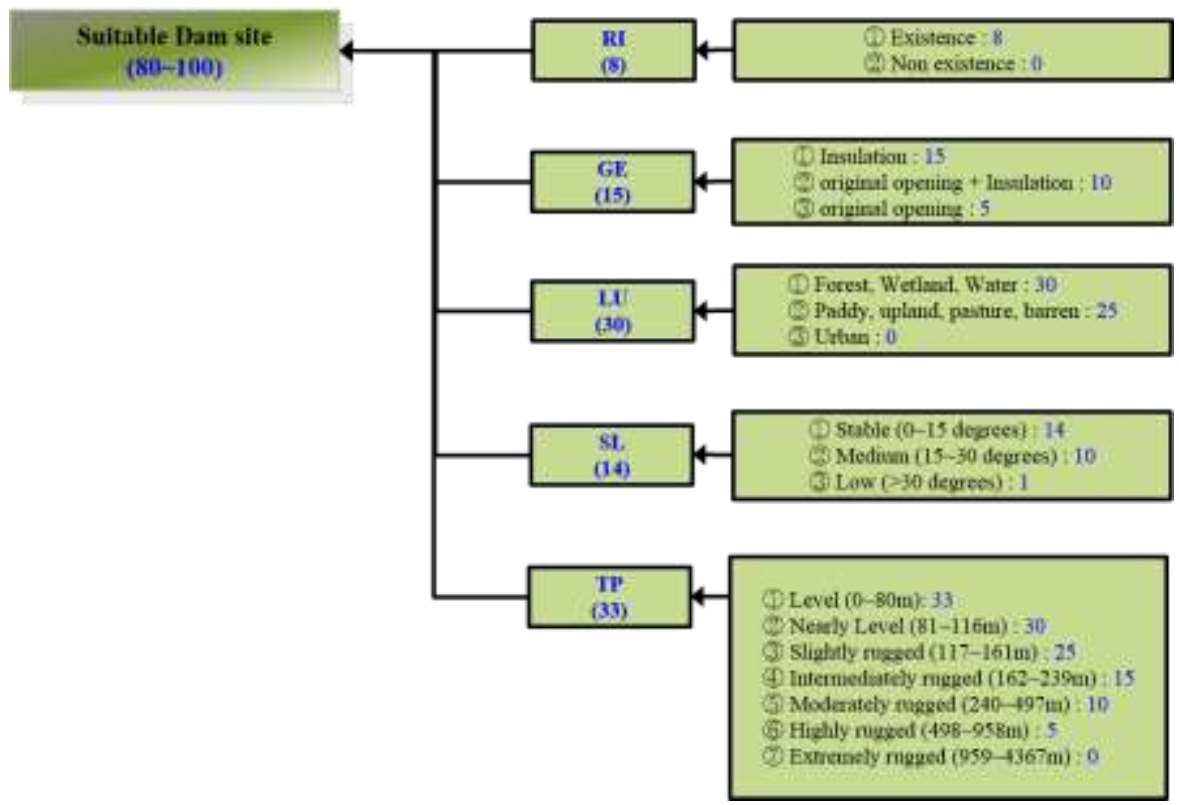

Fig. 1: The results of weight for each index

\subsection{Weighting assessment indexes}

The pair wise comparison matrices that is applied the opinions of experts about the evaluation indexes such as land cover (LC), hydrological geology (GE), slope (SL), river (RI) and topography (GE) are as follows in Table 1. The Consistency Index which indicates the reliability of the questionnaire was analyzed as 0.0317 . If this index is estimated lower than 0.1 , it is evaluated as having reliability between the indicators. The weights of the indicators calculated by the AHP technique are shown in Fig. 1.

TABLE 1: The example of pair wise comparison matrix

\begin{tabular}{llllll}
\hline \hline & LC & GE & SL & RI & TP \\
\hline LC & 1 & 3 & 2 & 3 & $1 / 2$ \\
GE & $1 / 3$ & 1 & 1 & 2 & $1 / 2$ \\
SL & $1 / 2$ & 1 & 1 & 2 & $1 / 2$ \\
RI & $1 / 3$ & $1 / 2$ & $1 / 2$ & 1 & $1 / 3$ \\
TP & 2 & 2 & 2 & $1 / 3$ & 1 \\
& & & \multicolumn{4}{c}{ Consistency Index $: 0.0317$} \\
\hline \hline
\end{tabular}

\section{Development of functional formula}

\subsection{Function of estimating suitable dam site}

Fig. 2 shows that in order to estimate suitable dam site, 5 indices such as RI, GE, LU, SL and TP as above determined were converted to gird and overlaid. Performance procedure for each index is as follows.

(1) The land cover map collected from ministry of environment is changed from polygon to raster type, and then "LC" is made with weighting method for each property.

(2) Hydrogeological map that is supplied by National Groundwater Information Center for people on the web is converted from polygon to raster type, and then the map applied weighting method for each item is transformed into "LC".

(3) Using "Slope" among "Spatial Analysis" tool of ArcGIS, DEM is changed into slope map and afterward "SL" is made with weighting method for each slope grade. 
(4) To reflect not only national and regional river maps but also stream order map, the maps concerning river are combined to 1 layer as a total river map. The map applied weighting method for each item is transformed into "RI".

(5) DEM is changed into "TP" using TRI technique suggested by Riley et al. (1999).

(6) Suitable dam site is estimated by overlapping structured "LC", "GE", "SL", "RI" and "TP" maps.

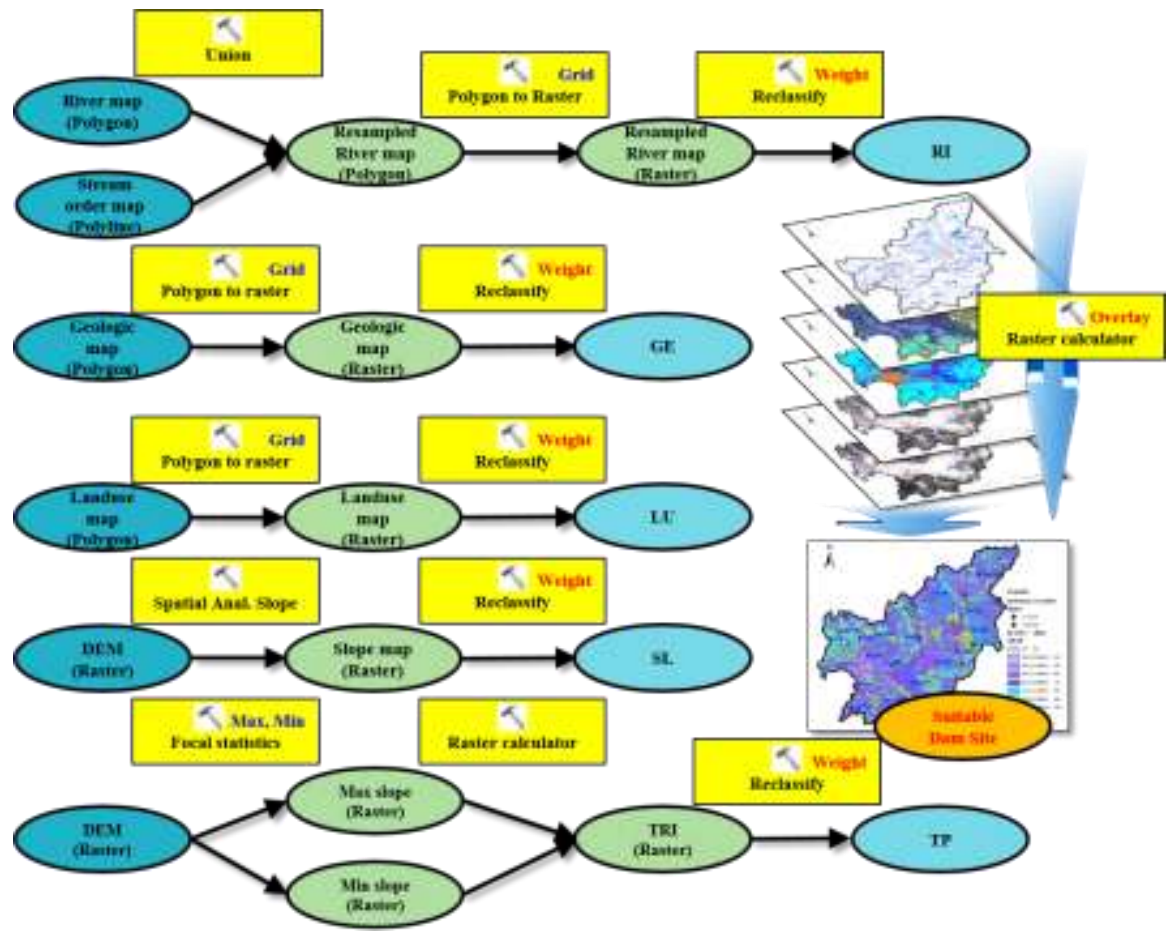

Fig. 2: Schematic diagram for suitable dam site

\subsection{Calibration and verification}

\subsection{Study area}

To calibrate and verify the function of estimating suitable dam site, in the present study, Kumho river watershed and Miryang river watershed is selected (Table 2). Calibration method is performed with adjusting the weight by comparing the results of estimated site with the existing facilities such as dam, reservoir and developed water pot. Verification method is conducted without adjusting the weight for other watershed.

\begin{tabular}{lll}
\multicolumn{2}{c}{ TABLE 2: Study watershed for calibration and verification } \\
\hline \hline Division & Study area & Watershed code \\
\hline Calibration & Kumho river watershed & 2012 \\
Verification & Miryang river watershed & 2021 \\
\hline \hline
\end{tabular}

\subsection{Construction of input data}

The input data for Kumho river and Miryang river watersheds are the total river map, hydrogeological map, land cover map and DEM, respectively.

\subsection{Calibration results}

Fig. 3(a) was calculated by overlapping maps of weighted "LC", "GE", "SL", "RI" and "TP". Weighted value of step 2 in Fig. 1 that is modified using trial and error method was calibrated. The calibrated results is Fig. 3(b), the existing dam, Youngcheon dam, is the best suitable dam site. The detailed calibration results are shown in Fig. 4, where ' $o$ ' is the location of the agricultural reservoir and ' $\square$ ' is the location of water supply dams. Fig. 6 (a) is an enlarged view of the western side of Kumho river watershed. Most of the results of the site selection of agricultural reservoirs and water supply dams are over 70 points, and the eastern side of Kumho river watershed 
is enlarged. Similar results were obtained in 6 (b). The total number of grids $(10 \times 10 \mathrm{~m})$ in Kumho river watershed totaled $2,269,555 \mathrm{~m}^{2}$, with a total of $15,626(2.07 \%)$ over 70 .

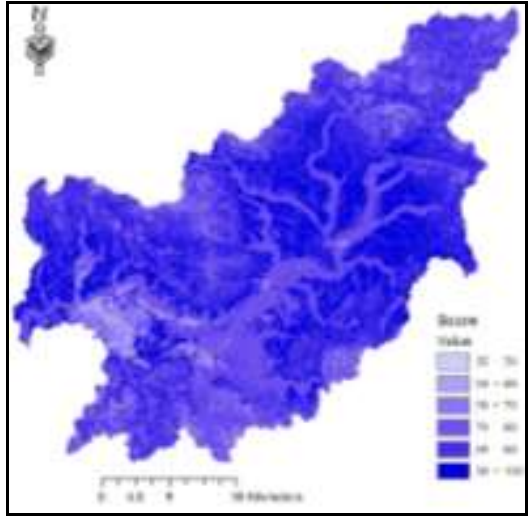

(a)

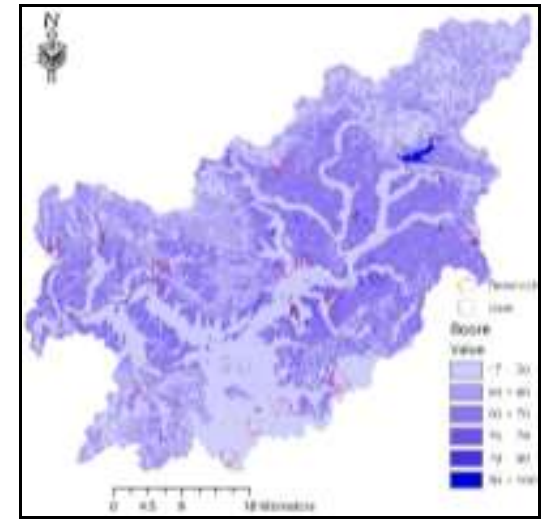

(b)

Fig. 3: The results of Kumho river watershed

(a) Before calibration, (b) After calibration

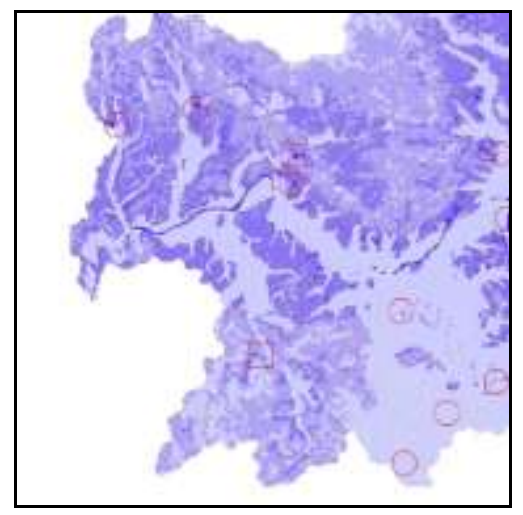

(a)

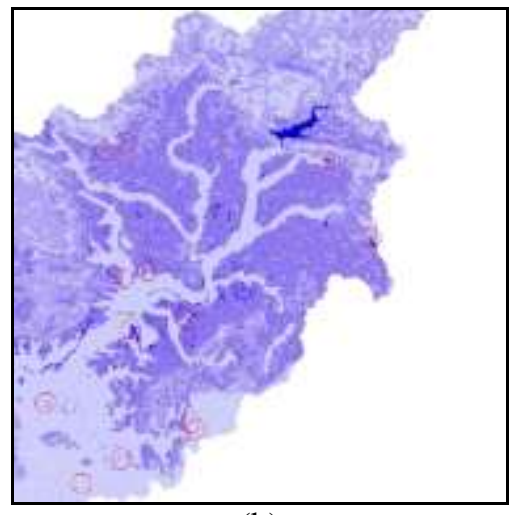

(b)

Fig. 4: The detailed results of Kumho river watershed

(a) West watershed, (b) East watershed

\subsection{Verification results}

Verification is stage that checking that don't change selected parameter and whether the suggested demands is conducted well at previous calibration phase, and it is a phase which judging suitability for comparing the real phenomenon with suggested the result. In the present study, verification target is Miryang river watershed, after the decided weight is applied as it is for previously revision, the result selecting suitable area of the dam for overlap weighted index is deducted. The total number of grids $((10 \times 10 \mathrm{~m}))$ in Miryang river watershed was 1,540,256, which was analyzed 98,709 (6.41\%) over 70 points. Fig. 7 shows the results of applying the site selection function to Miryang river watershed. Fig. 5 (a) shows the results of Miryang river watershed, and Fig. 5 (b) shows the watershed of Unmun dam with high score. The results obtained from the site selection function are overlaid on Google Earth and Fig.6 shows the comparison. Fig. 6 corresponds to the area around Unmun dam, reservoir part of Unmun dam represented over 79 points $(0.80 \%)$, and the dam site is selected 2 area at northeast and east of Unmun dam. It is judged that the selected Dam site is well formed water bowl. Also, Miryang dam shows that reservoir of Miryang dam and west of Miryang dam is selected suitable area. 


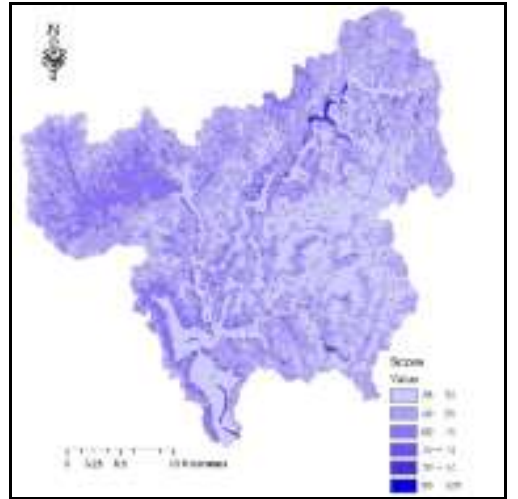

(a)

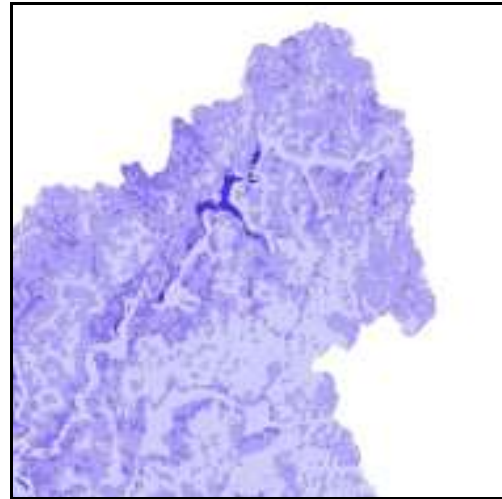

(b)

Fig. 5: The results of Miryang river watershed

(a) Overall, (b) Suitable dam site

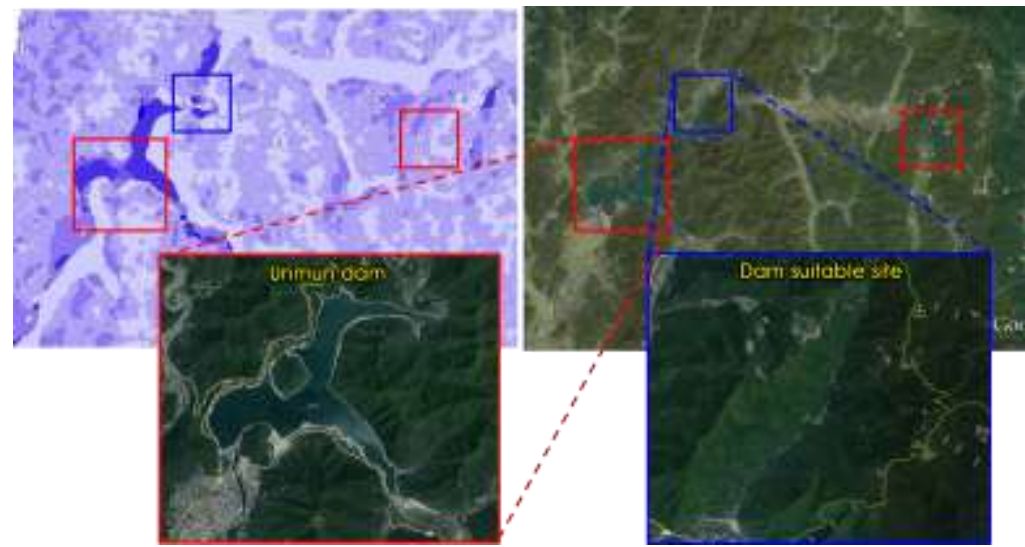

Fig. 6: The detailed results of Miryang river watershed I

TABLE 3: The results of verification

\begin{tabular}{lll}
\hline \hline Value & Count & Percent $(\%)$ \\
\hline $0-50$ & 478,235 & 31.0 \\
$51-60$ & 767,777 & 49.8 \\
$61-70$ & 279,526 & 18.1 \\
$71-80$ & 11,729 & 0.8 \\
$81-90$ & 2,250 & 0.1 \\
$91-100$ & 739 & 0.0 \\
Total & $1,540,256$ & 100.0 \\
\hline \hline
\end{tabular}

Here, Value is the result of applying to the suitable site selection function formula, and Count is the number of cells corresponding to the score of the suitable site selection function formula.

\subsection{Development of estimating suitable dam site}

In 4.1, the suitable site selection function formula was corrected for the watershed of the Kumho River, and In 4.2, the suitable site selection function formula was tested for the watershed of the Miryang River. LC is land cover, GE is hydrological geology, SL is slope, RI is river, and TP is represents the terrain corresponding to the watershed. Each index through converted to gird and weighting method was overlaid, and then a value of grid by function of estimating suitable dam site is calculated. We proposed the function of suitable dam site using girding and weighting though above mentioned method. This equation finally showed the CAL/VAL activity, weights, and overlapping processes, and the function formula is shown in Eq. (1). 


$$
Y=15 L C+30 G E+15 S L+20 R I+20 T I
$$

Where, $\mathrm{Y}$ is dam suitable site selection function formula, LC, GE, SL, RI, and TI represent weighted land cover, hydrologic geology, land slope, stream, and topography, respectively.

\section{Conclusions}

In the present study, the site conditions of the standard watershed dam watershed were analyzed using GIS, and indexes to select the dam suitable site was determined through site condition analysis and literature survey, etc. Also, calibration and verification were performed by applying a dam suitable site selection function formula to both standard watersheds. The results of the current study are summarized as follows.

(1) Using the AHP method a weighting method for the index of the dam suitable site is proposed to provide.

(2) The derived method can efficiently utilize topographic information such as digital map, soil map, land cover map and river map, etc., and can select various candidate sites visually while reducing time, budget and manpower.

\section{Acknowledgements}

This work was supported by the Brain Korea 21 Plus Project in the Division of Creative Low Impact Development and Management for Ocean Port City Infrastructures.

\section{References}

[1] E. Raheem and S. H. Khan, "Combining probability of emptiness and mean first overflow time of a dam to determine its capacity," Journal of Spatial Hydrology, vol.2, no.2, 2002.

[2] J. D. Lee, H. H. Lee and S. G. Kim, "Utilizing Geographic Information System for Analyzing Land Use Suitability in a Urban Area - A Case Study of Kumi City -," Journal of The Korean Association of Geographic Information Studies, vol.4, no.4, pp.29-38, 2001.

[3] J. H. Park and H. S. Choi, “Application of GIS for Land Suitability Analysis," Journal of Korea Planning Association, vol.39, no.1, pp.45-58, 1997.

[4] J. O. Lee, M. H. Seo and C, Han, "The Method of Site Selection for the Small-scaled Ground Water Development using Topography Factor,” Proceedings 2015 Korea Society of Surveying, pp.277-280, 2015.

[5] S. Iftikhar, "Site Suitability Analysis for Small Multipurpose Dams Using Geospatial Technologies," Journal of Remote Sensing \& GIS, pp.1-13, 2016.

[6] S. Lili, and Q. I. A. O. Jianping, "Vulnerability evaluation on regional landslides based on GIS and contribution weight superposition approach," Journal of Catastrophology, vol.24, no.3, pp.46-50, 2009.

[7] T. L. Saaty, "Decision making with the analytic hierarchy process," Int. J. Services Sciences, vol.1, no.1, pp.83, 2008. https://doi.org/10.1504/IJSSCI.2008.017590 